\title{
Analysis of Wheel Hub Motor Drive Application in Electric Vehicles
}

\author{
Yuechao Sun*, Man Li and Cong Liao \\ Mechanical and Electrical Engineering Department, Lingnan Normal University, Zhanjiang 524048, China \\ Corresponding Email: yuechaosun@sina.com
}

\begin{abstract}
Based on the comparative analysis of the performance characteristics of centralized and distributed drive electric vehicles, we found that the wheel hub motor drive mode of the electric vehicles with distributed drive have compact structure, high utilization ratio of interior vehicle space, lower center of vehicle gravity, good driving stability, easy intelligent control and many other advantages, hence in line with the new requirements for the development of drive performance of electric vehicles, and distributed drive will be the ultimate mode of electric vehicles in the future.
\end{abstract}

Keywords. Electric Vehicle, Drive Mode, Wheel Hub Motor, Development Analysis.

\section{Foreword}

Compared with conventional vehicles, electric vehicles have the advantages of high efficiency of energy conversion, low noise, zero emission, etc., and the load-carrying property and wide range speed control characteristics of motors can remove the mechanical devices such as clutch and gearbox, simplifying the structure and facilitating maintenance [1,2]. Driven by the dual pressures of energy and environment nowadays, the world's major automobile producing countries are developing electric vehicle industry with unprecedented efforts. Electric vehicles are creating a new pattern of the automobile industry, which will sure lead the main direction of the automobile industry development.

As the core component of an electric vehicle, the quality of driving motor has a great influence on the power, economical efficiency and safety of the electric vehicle. However, different from other industrial motors, the motor drive system of vehicle drive motor is not only affected by the size of vehicle structure, but shall also meet the operating conditions under complex conditions [3-6]. Therefore, in addition to the requirements of high efficiency, low mass, high power density, small size, good reliability and low cost of the drive motor, it shall also adapt to the frequent start, stop, climbing, acceleration and deceleration conditions of vehicles, which require a wide range of speed and high overload factor of automotive drive motor in order to meet the performance requirements of high torque under low speed or climbing or low torque under high speed $[7,8]$.

\section{Drive Mode}

According to the different installation locations of drive motor in electric vehicles, there are single-motor centralized drive and multi-motor distributed drive modes. Distributed drive is further divided into wheel side motor drive and wheel hub motor drive.

\subsection{Centralized drive}

Centralized drive is close to the conventional vehicle structure, in which the internal combustion engine is replaced by a motor, and the motor torque is transmitted to the drive wheel through the power train to drive the vehicle. It can be achieved by making a slight change based on the conventional vehicle structure, which has mature, safe and reliable operation technology, but has the shortcomings of small interior size, heavy mass, low transmission efficiency and complex control. 




1- Power battery,2- Drive motor,3-Clutch,4- Transmission,5- Differential

a Mechanical transmission with a clutch.



1- Power battery,2- Drive motor,3- Fixed speed ratio reducer 4- Differential

b Mechanical transmission without a clutch.



1-Power battery,2-Drive motor,3-Transmission and Differential

c Electromechanical integrated transmission.

Fig.1. Centralized drive transmission.

There are 3 transmission modes of centralized drive, see Figure ${ }^{[9]}$. Fig. 1 a shows the transmission mode with a clutch, the transmission of pure electric vehicle generally has 2-3 gear shifts, the clutch plays the role of breaking off power and reducing shift shock while shifting. Fig. $1 \mathrm{~b}$ eliminates the clutch and connects the motor to the fixed speed ratio reducer via the transmission shaft, reducing the power train mass and the transmission volume, thus increasing the space inside the vehicle. Fig. 1c integrates the motor, reducer and differential, drives the corresponding side wheel through the left and right axle shafts, respectively, and is compact in layout, mainly for small cars.

\subsection{Distributed drive}

Distributed drive transmits power to the corresponding wheel by integrating multiple motors in the vicinity of the wheel or rim, greatly shortening the transmission chain. According to the motor position and different transmission, it can be divided into wheel side motor drive and wheel hub motor drive.

\subsubsection{Wheel side motor drive}

Wheel side motor drive installs the drive motor on the side of the drive wheel of the subframe, and drives the corresponding side wheel with or without the reducer. The drive mode with a reducer connects the motor to the fixed speed ratio reducer and drives the corresponding side wheel through the axle shaft.

As shown in Figure $2[9,10]$, the two motors can drive the corresponding side wheel separately through the corresponding side reducer. The motor speed can be controlled independently, and the speed differential on the left and right axle shafts can be realized by an electronic differential. 


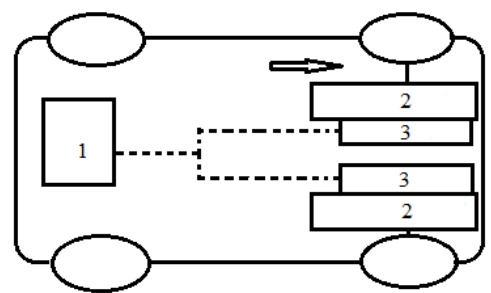

1-Power battery,2- Fixed speed ratio reducer,3- Drive motor a Layout of wheel rim motor drive.



1- Rim,2- Power battery,3- Reducer

$\mathrm{b}$ Schematic diagram of wheel rim motor drive assembly.

Fig. 2. Wheel side motor drive.

The vehicle transmission chain and transmission space of wheel side motor drive are further reduced, making the mechanical structure of the chassis simple, reducing the vehicle mass, achieving more reasonable layout, and improving the transmission efficiency. Audi R8e-tron pure electric sports car is driven by four asynchronous motors, with $100 \mathrm{~km}$ acceleration of only $4.8 \mathrm{~s}$.

\subsubsection{Wheel hub motor drive}

Wheel hub motor drive is the most advanced electric vehicle driving technology, which installs two, four or more motors in the wheel, direct driving wheels, commonly known as electric wheels, which is especially suitable for pure electric vehicles.



a Conventional vehicle drive.



b Wheel hub electric vehicle drive.

Fig. 3. Comparison of the drive of conventional vehicles and wheel hub electric vehicles.

Figure 3 shows a comparison of the chassis of conventional vehicles and vehicles driven by a wheel hub motor, the wheel hub motor drive completely eliminates the power train components such as clutch, transmission, differential and axle shafts, making the chassis structure simple, improving the transmission efficiency, reducing the vehicle mass, achieving more reasonable layout, and facilitating the realization of intelligent chassis and electrification control. Based on whether there is a retarding mechanism, wheel hub motor drive can be divided into direct drive and deceleration drive (deceleration drive electric wheel) [11].

The external rotor of the motor is mechanically connected with the wheel hub and has no deceleration structure, which is a direct drive mode, see Fig. 4a [9]. Motor speed is generally 1500r/min or so, due to the lack of retarding mechanism, driving structure is compact with high transmission efficiency. But large current is required at the start, climbing or under large loads, which could easily damage the battery and permanent magnets. In order to ensure a large start torque and good dynamic property, the requirements of the motor are high, and low-speed external rotor permanent magnet synchronous motor is generally adopted. 




a Direct-drive external rotor motor.



b Deceleration-driven inner rotor motor.

Fig. 4. Layout of wheel hub motor drive.

Deceleration drive is to installed a fixed speed ratio reducer between the motor and the wheel, playing the role of deceleration and torque-up. The deceleration device is generally a high reduction ratio planetary gear mechanism, see Fig. 4b [9]. The working speed of the motor is about $10000 \mathrm{r} / \mathrm{min}$, usually using high-speed inner rotor permanent magnet synchronous motor, the drive wheel hub drives the vehicle after deceleration and torque-up of motor output power. The motor is small, light and with high specific power of high-speed running. After deceleration and torque-up, the vehicle has good climbing ability, and it can guarantee the vehicle has a large steady torque when running at low speed. However, the structure is relatively complex, and the increase of unsprung mass affects the ride comfort and handling stability.

\section{Drive Performance and Development Analysis}

\subsection{Drive performance analysis}

Table 1 shows the performance comparison of the electric motors in different drive modes, and shows the transmission efficiency, economical efficiency and handling stability. Table 1 and the above drive modes show that: centralized drive vehicles are similar to the conventional internal combustion engine vehicles, the latter have many power train components, high cost, low transmission efficiency, complex control and other shortcomings.

Table 1. Performance comparison of electric vehicles' drive modes.

\begin{tabular}{|c|c|c|c|}
\hline $\begin{array}{c}\text { Performance } \\
\text { parameters }\end{array}$ & $\begin{array}{c}\text { Centrali } \\
\text { zed }\end{array}$ & $\begin{array}{l}\text { Distribute } \\
\mathrm{d} \text { wheel } \\
\text { rim motor } \\
\text { drive }\end{array}$ & $\begin{array}{l}\text { Distribute } \\
\mathrm{d} \text { wheel } \\
\text { hub motor }\end{array}$ \\
\hline $\begin{array}{l}\text { Transmission } \\
\text { chain length }\end{array}$ & Long & Short & $\begin{array}{c}\text { The } \\
\text { shortest }\end{array}$ \\
\hline $\begin{array}{l}\text { The interior space } \\
\text { utilization }\end{array}$ & General & High & High \\
\hline $\begin{array}{l}\text { Body centroid } \\
\text { height }\end{array}$ & General & Low & Low \\
\hline $\begin{array}{l}\text { Transmission } \\
\text { efficiency }\end{array}$ & Medium & $\begin{array}{l}\text { Highe } \\
\mathrm{r}\end{array}$ & High \\
\hline
\end{tabular}




\begin{tabular}{lccc}
\hline $\begin{array}{l}\text { Economical } \\
\text { efficiency }\end{array}$ & Better & Good & Good \\
$\begin{array}{l}\text { Kinetic } \\
\text { controllability }\end{array}$ & General & Good & Good \\
$\begin{array}{l}\text { Energy recovery } \\
\text { (regenerative }\end{array}$ & Yes & Yes & Yes \\
$\begin{array}{l}\text { braking) } \\
\text { Noise }\end{array}$ & Small & Small & Small \\
$\begin{array}{l}\text { Wheel drive } \\
\text { torque fluctuation }\end{array}$ & Small & Big & Big \\
$\begin{array}{l}\text { Wading } \\
\text { performance }\end{array}$ & Good & General & $\begin{array}{c}\text { Genera } \\
1\end{array}$ \\
\hline
\end{tabular}

Compared with centralized drive, wheel rim motor drive mode has short transmission chain, good economical efficiency, high interior space utilization, small braking energy feedback loss, but the transmission efficiency is not as high as wheel hub motor drive.

Wheel hub motor drive completely abolishes the power train components, integrates the motor, suspension system and brake system in the rim, achieving compact vehicle structure, lower center of gravity and improved driving stability. The wheel hub motor is connected to the power battery and the controller using a wire harness, as shown in Fig. 3b. This allows for more flexibility in the layout of the interior space and saving more space for occupants while improving ride comfort. Meanwhile, the movement of each wheel is independent from each other, with no rigid connection, the wheel driving force and braking force can be quickly optimized, assigned precisely and arbitrarily by computer and motor control systems as per the driving state, easy to implement by-wire steering, ABS, TCS, ESP and other functions, achieving flexible motor steering, reliable kinetic performance, and good handling stability. In addition, wheel hub drive can also achieve electrical braking, electromechanical composite braking and braking energy feedback, with low energy consumption and high braking energy recovery, energy conversion efficiency can reach $90 \%$ [12].

Although the vehicles with wheel hub motor drive have outstanding performance, the wheel hub motor, brake system and even suspension system are integrated in the wheel, resulting in significant increase of vehicle unsprung mass and rotary inertia of wheel rotating parts, thereby increasing the vibration amplitude along vertical direction of vertical, and even affecting the tire adhesion, which is not conducive to vehicle control and could also reduce ride comfort.

\subsection{Development analysis}

Wheel hub motor drive has unparalleled advantages compared with other drive modes, although there is yet no mature wheel hub drive automotive product applications, as a new advanced drive mode, wheel hub drive is a focus in the current domestic and international electric vehicles research. Many scholars at home and abroad have done a lot of research on the shortcomings of wheel hub motor drive, and put forward a series of corresponding improvement measures. For example: Nagaya et al [13] controlled vertical vibration negative effect caused by unsprung mass by making a vibration absorber using motor mass. Johansen, Yang et al [14-15] reduced the unsprung mass by converting the motor stator mass into the sprung mass through a special motor design. Zhao Yan'e et al [16] converted the wheel hub motor stator mass from unsprung mass to sprung mass by setting a vibration reduction mechanism in parallel with the suspension system. Luo Hong et al [17] proposed to take the entire motor mass as the sprung mass, namely to take the motor mass as the vibration absorber mass in the power driven system that directly drives wheel hub motor, with no additional mass. Shi Tianze et al [18-20] developed a special suspension and steering system that applies to wheel hub motor vehicles, which comprises a double-arm front suspension, torsion beam rear suspension and mechanical steering system.

In view of the problems of wheel hub motor drive, researchers are exploring, improving and developing from various aspects, including the development of high-torque wheel hub motor, the integration and control of intelligent chassis, the impact of non-spring mass on vehicle performance and other technologies. We believe that in the near future, researchers will explore a reasonable new technology to solve the current problems, give full play to the advantages of wheel hub motor drive, making it the ultimate drive mode of electric vehicles.

\section{Conclusion}

Electric vehicles that adopt wheel hub motor drive mode have compact structure, high utilization ratio of interior vehicle space, lower center of vehicle gravity, good driving stability, easy intelligent control and many other advantages, and have unique advantages in maintenance costs, safety, high-torque drive and other aspects compared with other drive modes. Therefore it is in line with the requirements for the development of small electric vehicle drive motor, high power density, high reliability, etc., which will sure be the ultimate drive mode of electric vehicles in the future. 


\section{References}

1. Chai Haibo, Yan Zhiguo, Kuang Mingwei et al. Development status of electric vehicle drive motors. Small \& Special Electrical Machines, 2013, 41(4): 52-57

2. Zhou Fengjun. Research on integrated control strategy of distributed drive electric vehicles based on two-tier structure. Beijing: Beijing Institute of Technology, 2014.

3. Luo Longfei, Yuan Shouhua. Application overview of electric vehicle drive motor and its control system. Automobile Applied Technology, 2014, 4: 5-7

4. Liu Jinfeng, Zhang Xueyi, Hu Jianlong. Development prospect of electric vehicle drive motor. Agricultural Equipment \& Vehicle Engineering, 2012, 50(10): 35-38

5. Santiago J, Bernhoff H, Ekergrrd B, et al. Electrical motor drivelines in commercial all-electric vehicles: a review. IEEE Trans Veh Technol, 2012,61(2):475-484.

6. Liu Gang. Study on driving and control system of switched reluctance motor in electric drive vehicles. Beijing: University of Science and Technology Beijing, 2015.

7. Wang Chengyuan, Xia Jiakuan, Sun Yibiao. Modern motor control technology. Beijing: China Machine Press, 2010.

8. Dr.-Ing.Klaus Webers, Dr.-Ing. Rainer Busch, Fort Integrated Vehicle Dynamics Control Realization. Research \& Advanced Engineering. 2003.

9. Xu Wei, Zhang Ruoping. Selection of transmission scheme for electric vehicles. Auto Engineer, 2014, 8: 54-56

10. Liu Hao, Zhong Zaijing, Jing Hui, et al. Dynamic characteristics simulation of wheel rim motor drive system in distributed drive electric vehicles. Automotive Engineering, 2014, 36(5): 597-607

11. He Ren, Zhang Ruijun. Research and development of wheel hub motor drive technology. Journal of Chongqing University of Technology (Natural Science), 2015, 29(7): 10-18

12. Hori Y. Future Vehicle driven by Electricity and Control-Research on 4 Wheel Motored 'UOT March II', 2004.

13. Nagaya G, Wakao Y, Abe A. Development of an in-wheel drive with advanced dynamic-damper mechanism.JSAE R eview,2003,24( 4) : 477-481.

14. Johansen $P$ R, Pattersib D, O' keefe C. The use of an axial flux permanent magnet in-wheel direct drive in an electric bicycle. Renewable Energy, 2001, 22(1/2/3):151- 157 .

15. Yang Y P, Luh Y P, Cheng C H. Design and control of axial flux brushless DC wheel motors for electric vehi cles-part I: multi-objective optimal design and analysis. IEEE Transaction on Magnetics, 2004, 40( 4) : 18731882 .

16. Zhao Yan'e, Zhang Jianwu, Han Xu. Design and research of dynamic vibration reduction mechanism of electric vehicles independently driven by wheel hub motors. Mechanical Science and Technology for Aerospace Engineering, 2008, 27(3): 395-398.

17. Luo Hong, Xie Dan, Ma Ying. Analysis and design of power transmission mechanism of dynamic absorber power wheels. Mechanical Science and Technology for Aerospace Engineering, 2014, 33(2): 249-253.

18. Shi Tianze. Design and performance matching of wheel hub motor drive electric vehicle suspension and steering system. Changchun: Jilin University, 2015.

19. Tan Di. Dynamic characteristics and structural optimization of wheel hub motor drive system with built-in suspension. Guangzhou: South China University of Technology, 2013.

20. Wang R, Chen Y, Feng D, et al. Development and performance characterization of an electric ground vehicle with independently actuated in-wheel motors. Journal of Power Sources, 2011,196(8):3962-3971. 